\title{
Targeting Interleukin-4 Receptor Alpha by Hybrid Peptide for Novel Biliary Tract Cancer Therapy
}

\author{
Kahori Seto, ${ }^{1,2}$ Junichi Shoda, ${ }^{3}$ Tomohisa Horibe, ${ }^{2}$ Eiji Warabi, ${ }^{4}$ Masayuki Kohno, ${ }^{2}$ \\ Toru Yanagawa, ${ }^{1}$ Hiroki Bukawa, ${ }^{1}$ Yasuni Nakanuma, ${ }^{5}$ and Koji Kawakami ${ }^{2}$ \\ ${ }^{1}$ Department of Oral and Maxillofacial Surgery, Clinical Sciences, University of Tsukuba, Ibaraki 305-8575, Japan \\ ${ }^{2}$ Department of Pharmacoepidemiology, Graduate School of Medicine and Public Health, Kyoto University, Yoshida Konoe-cho, \\ Sakyo-ku, Kyoto 606-8501, Japan \\ ${ }^{3}$ Medical Science, Faculty of Medicine, University of Tsukuba, Ibaraki 305-8575, Japan \\ ${ }^{4}$ Division of Biomedical Science, Faculty of Medicine, University of Tsukuba, Ibaraki 305-8575, Japan \\ ${ }^{5}$ Department of Human Pathology, Graduate School of Medical Science, Kanazawa University, Kanazawa 920-1192, Japan
}

Correspondence should be addressed to Koji Kawakami; kawakami.koji.4e@kyoto-u.ac.jp

Received 7 February 2014; Accepted 8 April 2014; Published 27 April 2014

Academic Editor: Chawalit Pairojkul

Copyright (C) 2014 Kahori Seto et al. This is an open access article distributed under the Creative Commons Attribution License, which permits unrestricted use, distribution, and reproduction in any medium, provided the original work is properly cited.

It is known that the interleukin- 4 receptor $\alpha$ (IL- $4 \mathrm{R} \alpha)$ is highly expressed on the surface of various human solid tumors. We previously designed novel IL-4R $\alpha$-lytic hybrid peptide composed of binding peptide to IL- $4 \mathrm{R} \alpha$ and cell-lytic peptide and reported that the designed IL-4R $\alpha$-lytic hybrid peptide exhibited cytotoxic and antitumor activity both in vitro and in vivo against the human pancreatic cancer cells expressing IL-4R $\alpha$. Here, we evaluated the antitumor activity of the IL-4R $\alpha$-lytic hybrid peptide as a novel molecular targeted therapy for human biliary tract cancer (BTC). The IL-4R $\alpha$-lytic hybrid peptide showed cytotoxic activity in six BTC cell lines with a concentration that killed $50 \%$ of all cells $\left(\mathrm{IC}_{50}\right)$ as low as $5 \mu \mathrm{M}$. We also showed that IL-4R $\alpha$-lytic hybrid peptide in combination with gemcitabine exhibited synergistic cytotoxic activity in vitro. In addition, intravenous administration of IL-4R $\alpha$-lytic hybrid peptide significantly inhibited tumor growth in a xenograft model of human BTC in vivo. Taken together, these results indicated that the IL- $4 \mathrm{R} \alpha$-lytic hybrid peptide is a potent agent that might provide a novel therapy for patients with BTC.

\section{Introduction}

Biliary tract cancer such as gallbladder cancer and extrahepatic bile duct cancer as well as intrahepatic bile duct cancer (one of the primary liver cancers) is likely to undergo metastasis to the peritoneum (peritoneal dissemination) or the liver at early stages and is often resistant to conventional chemotherapy and radiotherapy. These cancers have been thus viewed as intractable cancers unlikely to be cured completely. In Japan, the incidence of biliary tract cancer and intrahepatic bile duct cancer is about 10 out of every 100,000 people [1]. As for intrahepatic bile duct cancer, both the incidence and death rate have been rising in Japan in recent years, resembling the trend observed in western countries $[2,3]$. In Japan, gemcitabine and S-1 have recently begun to be used for anticancer chemotherapy, and these drugs are expected to prolong the survival period of patients as compared to existing anticancer drugs [4]. However, because of frequent adverse events of the hematological system arising from these drugs and because of compromised hepatic function often noted in patients with intrahepatic bile duct cancer due to accompanying liver cirrhosis and in those with extrahepatic bile duct cancer or gallbladder cancer due to accompanying obstructive cholestasis, treatment with these drugs has to be discontinued or stopped. To improve the outcome of treatment of these cancers, it is very important to identify the tumor biological factors involved in the progression (e.g., infiltration and metastasis) of the cancers and to develop new valid means of auxiliary treatment targeted at these factors.

Based on the immunohistochemical analysis showing that cultured BTC cell lines and cancerous epithelia in BTC tissue expressed receptors for interleukin-4 (IL-4) in situ at 
high densities, we previously tested the antitumor effects of IL-4-PE, a cytotoxin composed of an interleukin-4 (IL4) targeting moiety and a truncated form of Pseudomonas exotoxin, on human BTC cells [5]. The results showed a significant regression of established BTC tumors and a significant prolongation of the survival of animals with the disseminated tumors $[5,6]$. IL-4-PE was previously tested in the clinic for the treatment of human solid tumors [710]. However, against expectation of these promising results, the clinical application of IL-4-PE faced many challenges, including nonspecific toxicities and immunogenicity [11].

To overcome these issues, we have recently developed a "hybrid peptide," composed of target-binding and cytotoxic sequences containing cationic-rich $\mathrm{D}$ - and L-amino acids to form amphipathic partial $\alpha$-helices that disrupt the cancer cell membrane selectively and are stable when combined with a cancer-targeting moiety [12]. Peptide drugs are relatively easily synthesized using either recombinant or solidphase chemical synthesis techniques and the production costs are generally affordable when compared to antibodybased therapeutics [12]. The hybrid peptides targeting EGFR, transferrin receptor, Hsp90, neuropilin-1, and interleukin-4 receptor $\alpha$ (IL-4R $\alpha$ ) have shown cytotoxic activity in vitro and antitumor activity in vivo against human solid tumors [12-17]. The IL-4R $\alpha$-lytic hybrid peptide is composed of an IL- $4 \mathrm{R} \alpha$ binding moiety and a cellular-membrane-lytic moiety [17]. Although the biological significance of IL- $4 \mathrm{R} \alpha$ expression of cancer cells remains unclear, this receptor is a candidate applicable for molecular targeted cancer therapy.

Here, we describe the cytotoxic activity by IL- $4 \mathrm{R} \alpha$-lytic hybrid peptide toward BTC cell lines which overexpress IL$4 \mathrm{R} \alpha$ in vitro. We also show the synergetic effect of IL- $4 \mathrm{R} \alpha$ lytic hybrid peptide with gemcitabine against BTC cells in vitro and that this hybrid peptide induces the significant regression of established human xenograft BTC tumor model in mouse in vivo.

\section{Materials and Methods}

2.1. Cell Lines and Culture Conditions. The experiments were performed on 4 human cholangiocarcinoma cell lines, KMBC [18] from Dr. M. Kojiro (Kurume University School of Medicine, Kurume, Japan), Sk-ChA-1 [19] from Dr. A. Knuth (Johannes Gutenberg University, Mainz, Germany), CCKS-1 [20] from Dr. Y. Nakanuma (Kanazawa University Graduate School, Kanazawa, Japan), and KKU-100 [21, 22] from Dr. B. Sripa (Khon Kaen University, Thailand), and on 2 human gallbladder carcinoma cell lines: TGBC-1-TKB and TGBC44-TKB [23] from Dr. T. Todoroki (University of Tsukuba, Ibaraki, Japan). All BTC cells were cultured in RPMI 1640 medium containing $10 \%$ heat-inactivated fetal calf serum (Invitrogen, Carlsbad, CA, USA) in a humidified atmosphere with $5 \% \mathrm{CO}_{2}$ at $37^{\circ} \mathrm{C}$.

2.2. Peptides. IL-4R $\alpha$-lytic hybrid peptide, KQLIRFLKRLDRNGGGKLLLKLLKKLLKLLKKK (bold and underlined letters correspond to D-amino acids), and lytic peptide, KLLLKLLKKLLKLLKKK, were synthesized by Invitrogen
(Carlsbad, CA, USA). Peptides were dissolved in water and buffered to $\mathrm{pH} 7.4$ as described previously [17].

2.3. Immunoblot Analysis. Immunoblot analysis was carried out as described previously [5]. Briefly, whole-cell extracts were obtained using buffer containing $1 \%(\mathrm{v} / \mathrm{v})$ Triton X$100,0.1 \%(\mathrm{w} / \mathrm{v})$ SDS, and $0.5 \%(\mathrm{w} / \mathrm{v})$ sodium deoxycholate, separated by SDS/PAGE, and transferred onto a PVDF membrane. IL-4R $\alpha$ antibody was used at dilution 1:100 (Santa Cruz Biotechnology, CA, USA) and $\beta$-actin was used as the internal control (R\&D Systems, Minneapolis, MN, USA). After treatment with horseradish peroxidaseconjugated anti-mouse IgG antibody, proteins were visualized on Hyperfirm using an enhanced chemiluminescence/western blotting system (GE Healthcare, Piscataway, NJ, USA).

2.4. Cell Viability Assay. Cell viability assay was performed as described previously [12]. Briefly, cells were seeded into 96-well plates at $3 \times 10^{3}$ cells per well in $90 \mu \mathrm{L}$ medium and incubated at $37^{\circ} \mathrm{C}$ for 24 hours. Each peptide (IL- $4 \mathrm{R} \alpha$ lytic hybrid peptide and lytic peptide) was diluted in $10 \mu \mathrm{L}$ culture medium and added to the cells. The concentration range of peptide we used was from 0 to $20 \mu \mathrm{M}$. After 72 hours of incubation, the cell viability assay using WST-8 solution (Nacalai Tesque, Kyoto, Japan) was performed.

2.5. Combination Assay of Peptide and Gemcitabine. The in vitro cytotoxic activity of IL- $4 \mathrm{R} \alpha$-lytic hybrid peptide and gemcitabine was measured as cell viability assay. The synergistic effect of IL- $4 \mathrm{R} \alpha$-lytic hybrid peptide and gemcitabine was assessed at a concentration ratio of $1: 1$, using the combination index $(\mathrm{CI})$, where $\mathrm{CI}<1, \mathrm{CI}=1$, and $\mathrm{CI}>1$ indicate synergistic, addictive, and antagonistic effects, respectively. The CI value was calculated as described previously [24].

2.6. Antitumor Activity of IL-4R $\alpha$-Lytic Hybrid Peptide in Xenografted Tumor Model of Human BTC. Animal experiments were carried out in accordance with the guidelines of Tsukuba University. $1 \times 10^{6}$ TGBC-44-TKB cells resuspended in $150 \mu \mathrm{L}$ phosphate-buffered saline were inoculated subcutaneously into the flank region of 4- to 6-week-old athymic female nude mice weighing 17-20 g. When the tumor reached $20-60 \mathrm{~mm}^{3}$ in volume, the animals were assigned randomly to 3 groups: saline (control) and IL-4R $\alpha$-lytic hybrid peptide ( 2 or $5 \mathrm{mg} / \mathrm{kg}$ ) injected intravenously ( $50 \mu \mathrm{L} /$ injection) three times a week for a total of nine times. Each group had 6 animals $(n=6)$. Tumors were measured with a caliper and the tumor volume (in $\mathrm{mm}^{3}$ ) was calculated using the formula length $\times$ width $^{2} \times 0.5$.

2.7. Statistics. Values were given as mean \pm SD (standard deviation), and the differences were analyzed using a one-way ANOVA with Dunnett's test. Differences were considered to be statistically significant at $P<0.05$. 
TABLE 1: Cytotoxic activity of IL-4R $\alpha$-lytic hybrid peptide against BTC.

\begin{tabular}{|c|c|c|c|}
\hline \multirow{2}{*}{ Cell line } & \multicolumn{2}{|c|}{$\mathrm{IC}_{50}(\mu \mathrm{M})$} & \multirow{2}{*}{$\begin{array}{c}\mathrm{IC}_{50} \text { ratio } \\
\text { (Lytic/IL-4R } \alpha \text {-lytic) }\end{array}$} \\
\hline & Lytic peptide alone & IL- $4 \mathrm{R} \alpha$-lytic peptide & \\
\hline TGBC-1-TKB & $16.99 \pm 1.28$ & $2.17 \pm 0.54$ & 7.83 \\
\hline TGBC-44-TKB & $21.37 \pm 4.91$ & $3.27 \pm 0.51$ & 6.53 \\
\hline CCKS-1 & $15.83 \pm 0.02$ & $2.73 \pm 1.26$ & 5.80 \\
\hline KKU-100 & $18.93 \pm 3.85$ & $2.99 \pm 1.01$ & 6.34 \\
\hline KMBC & $18.50 \pm 1.65$ & $3.25 \pm 1.36$ & 5.69 \\
\hline SK-1 & $13.44 \pm 0.42$ & $4.47 \pm 0.40$ & 3.00 \\
\hline
\end{tabular}

$\mathrm{IC}_{50}$ values (peptide concentration inducing $50 \%$ inhibition of control cell growth) are represented as mean $\pm \mathrm{SD}$ from triplicate determinations.

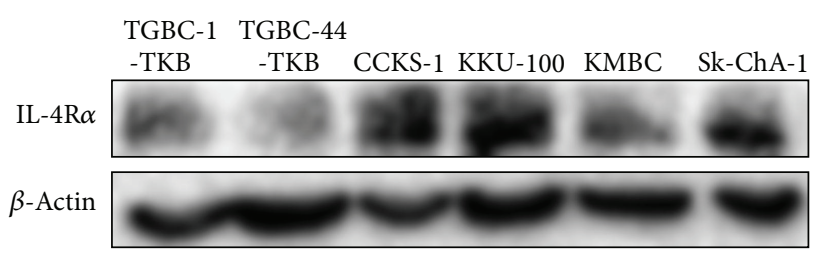

Figure 1: Expression levels of IL-4R $\alpha$ in BTC cells. Cell lysates were prepared from six BTC cell lines. $\beta$-Actin was used as an internal control.

\section{Results}

3.1. Expression of $I L-4 R \alpha$ in BTC Cell Lines. Immunoblot analysis demonstrated that IL- $4 \mathrm{R} \alpha$ protein is expressed in all cultured BTC cell lines used in this study. As shown in Figure 1, the expression levels of IL- $4 \mathrm{R} \alpha$ protein were the highest in intrahepatic cholangiocarcinoma cell lines (CCKS1 and KKU-100) among tested cell lines. On the other hand, it was also confirmed that gallbladder carcinoma cell lines (TGBC-1-TKB and TGBC-44-TKB) and extrahepatic cholangiocarcinoma cell lines (KMBC and Sk-ChA-1) expressed IL$4 \mathrm{R} \alpha$, although the expression levels were lower than those of CCKS-1 and KKU-100 cells.

3.2. Cytotoxic Activity of IL-4R $\alpha$-Lytic Hybrid Peptide in BTC Cell Lines. To assess the in vitro cytotoxic activity of IL$4 \mathrm{R} \alpha$-lytic hybrid peptide to BTC cell lines, the WST assay was performed using BTC cell lines treated with IL- $4 \mathrm{R} \alpha$ lytic hybrid peptide and lytic peptide (Figure 2). TGBC-1TKB, TGBC-44-TKB, CCKS-1, KKU-100, and KMBC were sensitive to IL-4R $\alpha$-lytic hybrid peptide; the concentration that killed $50 \%$ of all cells $\left(\mathrm{IC}_{50}\right)$ was less than $3.5 \mu \mathrm{M}$. SkChA- 1 was also sensitive to IL- $4 \mathrm{R} \alpha$-lytic hybrid peptide with an $\mathrm{IC}_{50}$ of less than $4.5 \mu \mathrm{M}$. In contrast, optimal cell killing was not induced in these cells by lytic peptide. The cytotoxic activity of the hybrid peptide was strongly enhanced when compared with that of the lytic peptide. The cytotoxic activity of IL- $4 \mathrm{R} \alpha$-lytic hybrid peptide increased 3.0-7.8-fold stronger than that of lytic peptide in BTC cell lines (Table 1).

3.3. Synergistic Cytotoxicity of IL-4R $\alpha$-Lytic Hybrid Peptide and Gemcitabine in BTC Cells. Gemcitabine alone mediated a dose-dependent cytotoxicity with $\mathrm{IC}_{50}$ of $12 \mathrm{nM}$ in SkChA-1. When it combined with IL-4R $\alpha$-lytic hybrid peptide,
TABLE 2: Combination therapy of hybrid peptide and GEM.

\begin{tabular}{lcc}
\hline & IC $_{50}$ & CI \\
\hline IL-4R hybrid peptide $(\mu \mathrm{M})$ & 4.47 & \\
Gemcitabine $(\mathrm{nM})$ & 12.2 & \\
IL-4R hybrid peptide $(\mu \mathrm{M})+$ gemcitabine $0.3 \mathrm{nM}$ & 4.29 & 0.95 \\
IL-4R hybrid peptide $(\mu \mathrm{M})+$ gemcitabine $3 \mathrm{nM}$ & 3.25 & 0.75 \\
\hline
\end{tabular}

$\mathrm{CI}$ (combination index) $<1, \mathrm{CI}=1$, and $\mathrm{CI}>1$ indicate synergistic, addictive, and antagonistic effect, respectively.

cytotoxicity in Sk-ChA-1 was greatly enhanced (Figure 3). $\mathrm{IC}_{50}$ of IL- $4 \mathrm{R} \alpha$-lytic hybrid peptide was 4.29 and $3.25 \mu \mathrm{M}$ by adding 0.3 and $3 \mathrm{nM}$ of gemcitabine, respectively (Table 2). The combination index was $<1$ at all concentrations of gemcitabine. The same phenomenon was also observed in TGBC-44-TKB (data not shown).

3.4. In Vivo Antitumor Activity by IL-4R $\alpha$-Lytic Hybrid Peptide in a Human BTC Xenograft Model. Following the observation that IL- $4 \mathrm{R} \alpha$-lytic hybrid peptide was remarkably cytotoxic to BTC cell lines in vitro (Figure 2), the antitumor activity of the hybrid peptide was assessed in a xenograft model of human BTC. TGBC-44-TKB cells were inoculated subcutaneously into athymic nude mice and then the animals were treated with IL-4R $\alpha$-lytic hybrid peptide by intravenous injection. As shown in Figure 4, tumors grew aggressively in control mice injected with saline alone, reaching a volume of $1285 \mathrm{~mm}^{3}$ by day 22 . In contrast, mice treated with IL- $4 \mathrm{R} \alpha$ lytic hybrid peptide showed significant tumor regression at both dosages: mean tumor volumes were $1025 \mathrm{~mm}^{3}(2 \mathrm{mg} / \mathrm{kg})$ and $594 \mathrm{~mm}^{3}(5 \mathrm{mg} / \mathrm{kg})$ on day 22 . The tumor volume was inhibited significantly at a dose of $5 \mathrm{mg} / \mathrm{kg}(P<0.05)$. No other abnormalities, such as loss of appetite and body weight, were observed in mice injected with IL-4R $\alpha$-lytic hybrid peptide (data not shown). The number of leukocytes (the mean $\left(\times 10^{3}\right)$ and SD values) after the experiments is as follows: control group: $5.1 \pm 2.1,2 \mathrm{mg} / \mathrm{kg}$ group: $5.6 \pm 4.0$, and $5 \mathrm{mg} / \mathrm{kg}$ group: $6.6 \pm 4.7$, and there are no significant differences in each group. Histological analysis also showed no side effects in tissue from the major organs, including liver and kidney, which were obtained from mice treated with intravenous administration of IL- $4 \mathrm{R} \alpha$-lytic hybrid peptide 


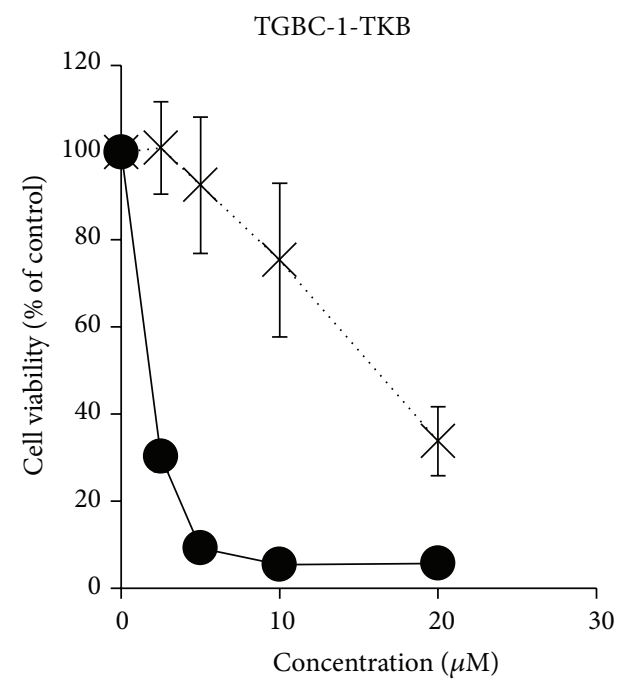

(a)

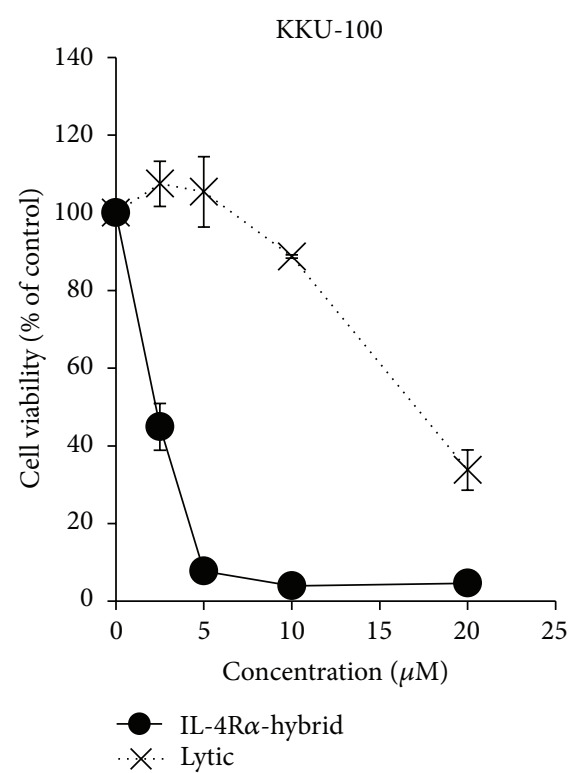

(d)

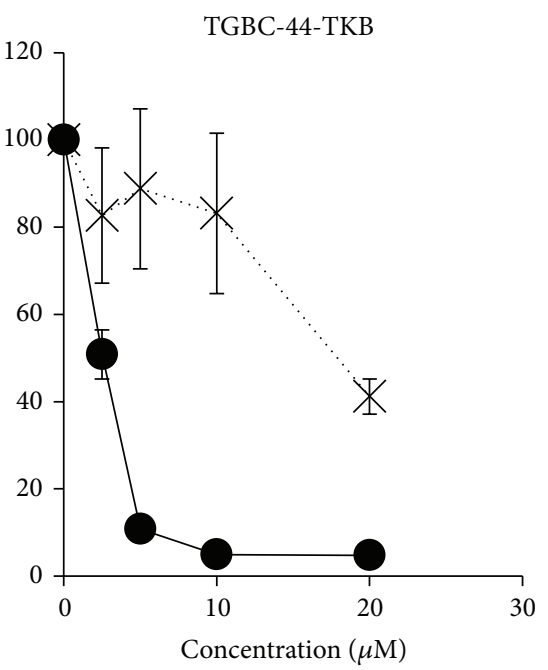

(b)

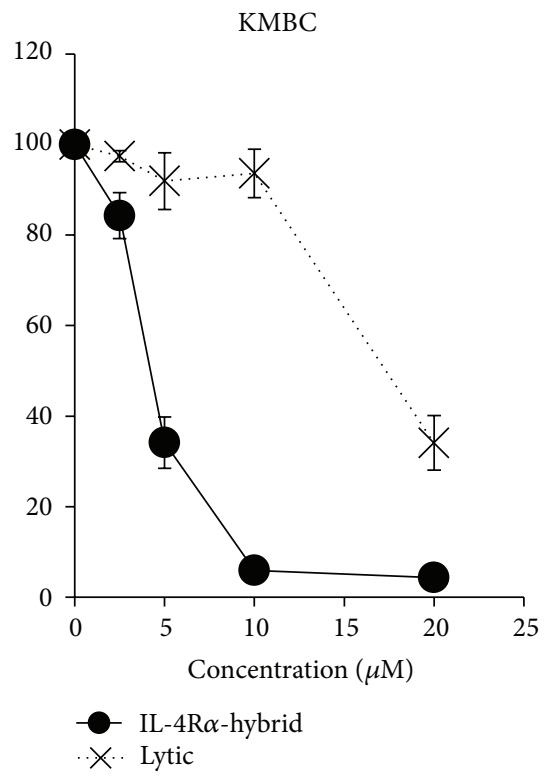

(e)

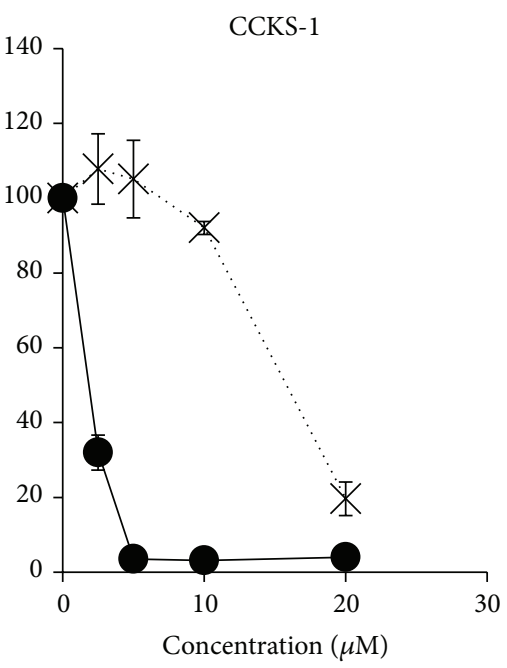

(c)

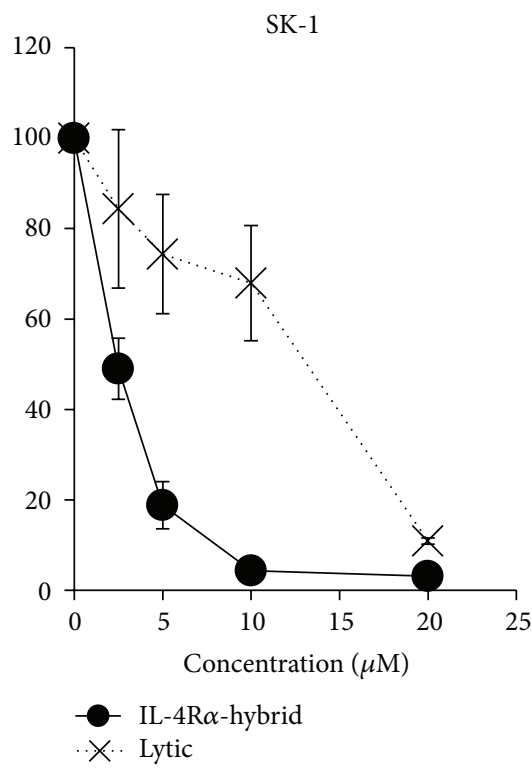

(f)

FIGURE 2: Cytotoxic activity of IL-4R $\alpha$-lytic hybrid peptide. Six BTC cell lines were cultured with various concentrations of IL-4R $\alpha$-lytic hybrid peptide or lytic peptide $(0-20 \mu \mathrm{M})$ for $72 \mathrm{~h}$, and cytotoxic activity was assessed using WST- 8 reagent. The results are represented as mean \pm SD (bars) of triplicate determinations, and the assay was repeated three times.

(data not shown). These results demonstrated that IL-4R $\alpha$ lytic hybrid peptide induced an effective antitumor activity in a mouse xenograft model of BTC.

\section{Discussion}

Therapeutic options for BTC are unsatisfactory, and the survival outcome is therefore poor. Effective therapeutic approaches against this aggressive disease are urgently needed. We previously demonstrated that human BTC tissue specimens expressed high levels of IL-4 receptor compared to normal gallbladders [5]. These observations were also confirmed in cultured human BTC cell lines that expressed IL-4R by immunoblot analysis. Immunohistochemical analysis showed overexpression of IL- $4 \mathrm{R}$ in a large proportion (50-63\%) of human BTC tissue specimens. Following the results of preclinical study for treatment of BTC with IL-4PE [5], the efficacy of IL- 4 R $\alpha$-lytic hybrid peptide against human BTC was evaluated in preclinical models in this study.

Using the approach of selective receptor targeting, we have tested the efficacy of IL- $4 \mathrm{R} \alpha$-lytic hybrid peptide on 


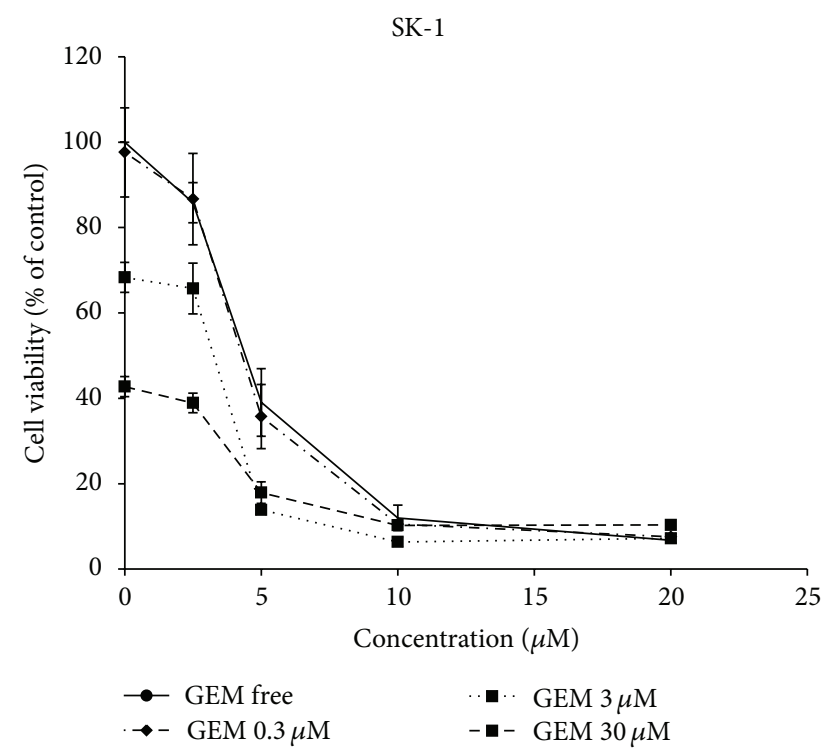

FIGURE 3: Cytotoxic activity by combination therapy of IL-4R $\alpha$ lytic hybrid peptide with gemcitabine. SK-1 was incubated with various concentrations of IL- $4 \mathrm{R} \alpha$-lytic hybrid peptide $(0-20 \mu \mathrm{M})$ and gemcitabine $(0-30 \mathrm{nM})$. The results are represented as mean \pm SD (bars) of triplicate determinations, and the assay was repeated three times.

BTC cells. The overexpression of IL-4R $\alpha$ in BTC cell lines sensitized them to the cytotoxic effect of this peptide, which correlated with the level of IL- $4 \mathrm{R} \alpha$ expression. The in vitro cytotoxicity of this peptide was assessed for 6 cultured BTC cell lines (Figure 1). KMBC and CCKS-1 cell lines showing higher levels of IL-4R $\alpha$ expression showed higher sensitivity ( $\mathrm{IC}_{50}$ of IL- $4 \mathrm{R} \alpha$-lytic hybrid peptide toward these cancer cells was approximately $2 \mu \mathrm{M}$, shown in Table 1 ). However the degree of the effect of IL-4R $\alpha$-lytic hybrid peptide against each BTC cell line is hardly different. These observations indicate that abundant IL- $4 \mathrm{R} \alpha$ expression in BTC tumors will facilitate efficient targeting by this hybrid peptide. We previously reported that IL- $4 \mathrm{R} \alpha$-lytic had effective cytotoxic activity toward cancer cells expressing IL$4 \mathrm{R} \alpha$ and that enhancement of the IL- $4 \mathrm{R} \alpha$-lytic peptideinduced cytotoxicity correlates well with the expression levels of IL-4R $\alpha$ [17]. We also previously showed the specificity of this hybrid peptide between normal and cancer cells by binding assay [25]. Moreover, it was demonstrated that intravenous administration of this hybrid peptide at $5 \mathrm{mg} / \mathrm{kg}$ dramatically inhibited the growth of TGBC44-TKB tumors in vivo (Figure 4). Histologic analysis also showed no abnormal changes in the tissue of major organs obtained from mice treated with the hybrid peptide (data not shown).

In this study, IL-4R $\alpha$-lytic hybrid peptide in combination with gemcitabine exhibited synergistic cytotoxic activity in vitro (Figure 3). Gemcitabine (Gemzar) is a widely accepted first-line therapy for advanced BTC, although the median survival time is not favorable [26]. Most studies using a single agent showed a low response rate and little effect on patient survival in advanced adenocarcinoma. It has recently been

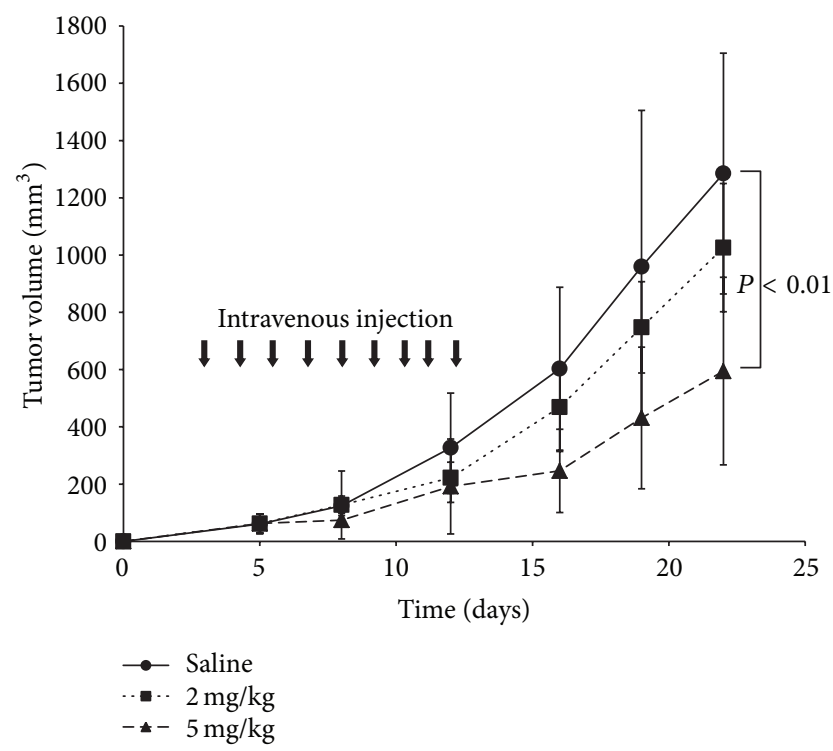

FIgURE 4: Antitumor activity of IL- $4 \mathrm{R} \alpha$-lytic hybrid peptide in tumor xenograft model in vivo. TGBC-44-TKB were implanted subcutaneously into athymic nude mice. Intravenous injection of saline and IL- $4 \mathrm{R} \alpha$-lytic hybrid peptide $(2 \mathrm{mg} / \mathrm{kg}$ or $5 \mathrm{mg} / \mathrm{kg}$ ) is indicated by the arrows. Data are expressed as mean $\pm \operatorname{SD}(n=6$ animals in each group).

reported that cisplatin plus gemcitabine is associated with a significant survival advantage as compared with gemcitabine alone [4]. Moreover, several clinical trials using a combined approach of molecular target therapy with gemcitabine and other drugs have been initiated [27, 28]. Previously, IL-4$\mathrm{PE}$ was shown to exert a synergistic effect with gemcitabine against the in vitro and in vivo pancreatic cancer models [28]. The results of this study support our observations of gemcitabine synergizing with IL- $4 \mathrm{R} \alpha$-lytic hybrid peptide on BTC cells, although the precise mechanism of the synergistic effect of gemcitabine with this hybrid peptide still remains obscure. It is known that gemcitabine inhibits DNA synthesis through inhibition of ribonucleotide reductase and depletion of deoxynucleotide pools [29]. It is suggested that the inhibition effect by gemcitabine in cancer cells might be exerted synergetically with the disintegration activity toward cancer cell membrane by IL-4R $\alpha$-lytic hybrid peptide $[12,17]$. Thus, it is possible that gemcitabine enhances cell death induced by IL-4R $\alpha$-lytic hybrid peptide. Considering cancer cell death, the combination therapy of these drugs, which act through different mechanisms, may be a beneficial treatment option for patients with BTC.

\section{Conclusions}

Our current data describe that IL-4R $\alpha$ is overexpressed in BTC cell lines in vitro, and BTC cells which overexpress the receptor can be successfully targeted with IL-4R $\alpha$-lytic hybrid peptide both in vitro and in vivo. IL-4R $\alpha$-lytic hybrid peptide induces regression of the established mouse model of BTC tumor. Thus, the findings of this study will assist and are 
available for elucidation of novel and effective BTC therapy targeting IL- $4 \mathrm{R} \alpha$ by IL- $4 \mathrm{R} \alpha$-lytic hybrid peptide.

\section{Conflict of Interests}

The authors declare that there is no conflict of interests regarding the publication of this paper.

\section{Acknowledgments}

The authors thank Nana Ohkubo (Department of Clinical Sciences and Molecular Cellular Physiology, Tsukuba University) for technical assistance or advice with tissue culturing and in vivo experiments. This work was supported in part by Grants-in-Aid for Scientific Research from the Ministry of Education, Culture, Sports, Science and Technology, Japan (nos. 23390318, 24390323, 25282212, 25293278, and 24390449).

\section{References}

[1] "Japan VSo. Tokyo (Japan): Japanese Ministry of Health and Welfare: Statistics Assoc., 1998.

[2] T. Patel, "Increasing incidence and mortality of primary intrahepatic cholangiocarcinoma in the United States," Hepatology, vol. 33, no. 6, pp. 1353-1357, 2001.

[3] S. D. Taylor-Robinson, M. B. Toledano, S. Arora et al., "Increase in mortality rates from intrahepatic cholangiocarcinoma in England and Wales 1968-1998," Gut, vol. 48, no. 6, pp. 816-820, 2001.

[4] J. Valle, H. Wasan, D. H. Palmer et al., "Cisplatin plus gemcitabine versus gemcitabine for biliary tract cancer," The New England Journal of Medicine, vol. 362, no. 14, pp. 1273-1281, 2010.

[5] K. Ishige, J. Shoda, T. Kawamoto et al., "Potent in vitro and in vivo antitumor activity of interleukin-4-conjugated Pseudomonas exotoxin against human biliary tract carcinoma," International Journal of Cancer, vol. 123, no. 12, pp. 2915-2922, 2008.

[6] T. Shimamura, R. E. Royal, M. Kioi, A. Nakajima, S. R. Husain, and R. K. Puri, "Interleukin-4 cytotoxin therapy synergizes with gemcitabine in a mouse model of pancreatic ductal adenocarcinoma," Cancer Research, vol. 67, no. 20, pp. 99039912, 2007.

[7] R. J. Kreitman, "Immunotoxins in cancer therapy," Current Opinion in Immunology, vol. 11, no. 5, pp. 570-578, 1999.

[8] F. Weber, A. Asher, R. Bucholz et al., "Safety, tolerability, and tumor response of IL4-Pseudomonas exotoxin (NBI-3001) in patients with recurrent malignant glioma," Journal of NeuroOncology, vol. 64, no. 1-2, pp. 125-137, 2003.

[9] P. Attia, D. J. Powell Jr., A. V. Maker, R. J. Kreitman, I. Pastan, and S. A. Rosenberg, "Selective elimination of human regulatory $\mathrm{T}$ lymphocytes in vitro with the recombinant immunotoxin LMB2," Journal of Immunotherapy, vol. 29, no. 2, pp. 208-214, 2006.

[10] R. J. Kreitman, "Immunotoxins in cancer therapy," Current Opinion in Immunology, vol. 11, no. 5, pp. 570-578, 1999.

[11] S. Choudhary, M. Mathew, and R. S. Verma, "Therapeutic potential of anticancer immunotoxins," Drug Discovery Today, vol. 16, no. 11-12, pp. 495-503, 2011.
[12] M. Kohno, T. Horibe, M. Haramoto et al., "A novel hybrid peptide targeting EGFR-expressing cancers," European Journal of Cancer, vol. 47, no. 5, pp. 773-783, 2011.

[13] M. Kawamoto, T. Horibe, M. Kohno, and K. Kawakami, "A novel transferrin receptor-targeted hybrid peptide disintegrates cancer cell membrane to induce rapid killing of cancer cells," BMC Cancer, vol. 11, article 359, 2011.

[14] T. Horibe, M. Kohno, M. Haramoto, K. Ohara, and K. Kawakami, "Designed hybrid TPR peptide targeting Hsp90 as a novel anticancer agent," Journal of Translational Medicine, vol. 9, article 8, 2011.

[15] N. Tada, T. Horibe, M. Haramoto, K. Ohara, M. Kohno, and K. Kawakami, "A single replacement of histidine to arginine in EGFR-lytic hybrid peptide demonstrates the improved anticancer activity", Biochemical and Biophysical Research Communications, vol. 407, no. 2, pp. 383-388, 2011.

[16] H. Ueyama, T. Horibe, O. Nakajima, K. Ohara, M. Kohno, and K. Kawakami, "Semaphorin 3A lytic hybrid peptide binding to neuropilin-1 as a novel anti-cancer agent in pancreatic cancer," Biochemical and Biophysical Research Communications, vol. 414, no. 1, pp. 60-66, 2011.

[17] L. Yang, T. Horibe, M. Kohno et al., "Targeting interleukin4 receptor $\alpha$ with hybrid peptide for effective cancer therapy," Molecular Cancer Therapeutics, vol. 11, no. 1, pp. 235-243, 2012.

[18] H. Yano, M. Maruiwa, A. Iemura, A. Mizoguchi, and M. Kojiro, "Establishment and characterization of a new human extrahepatic bile duct carcinoma cell line (KMBC)," Cancer, vol. 69, no. 7, pp. 1664-1673, 1992.

[19] A. Knuth, H. Gabbert, W. Dippold et al., "Biliary adenocarcinoma. Characterisation of three new human tumor cell lines," Journal of Hepatology, vol. 1, no. 6, pp. 579-596, 1985.

[20] K. Saito, H. Minato, N. Kono, Y. Nakanuma, F. Ishida, and M. Kosugi, "Establishment of the human cholangiocellular carcinoma cell line (CCKS1)," Kanzo, vol. 34, no. 2, pp. 122-129, 1993 (Japanese).

[21] B. Sripa, S. Leungwattanawanit, T. Nitta et al., "Establishment and characterization of an opisthorchiasis-associated cholangiocarcinoma cell line (KKU-100)," World Journal of Gastroenterology, vol. 11, no. 22, pp. 3392-3397, 2005.

[22] N. Tepsiri, L. Chaturat, B. Sripa et al., "Drug sensitivity and drug resistance profiles of human intrahepatic cholangiocarcinoma cell lines," World Journal of Gastroenterology, vol. 11, no. 18, pp. 2748-2753, 2005.

[23] N. Koike, T. Todoroki, T. Kawamoto et al., "The invasion potentials of human biliary tract carcinoma cell lines: correlation between invasiveness and morphologic characteristics," International Journal of Oncology, vol. 13, no. 6, pp. 1269-1274, 1998.

[24] T. Fujisawa, H. Nakashima, A. Nakajima, B. H. Joshi, and R. K. Puri, "Targeting IL-13R $\alpha 2$ in human pancreatic ductal adenocarcinoma with combination therapy of IL-13-PE and gemcitabine," International Journal of Cancer, vol. 128, no. 5, pp. 1221-1231, 2011.

[25] K. Seto, J. Shoda, T. Horibe et al., "Interleukin-4 receptor -based hybrid peptide effectively induced antitumor activity in head and neck squamous cell carcinoma," Oral Oncology, vol. 29, pp. 2147-2153, 2013.

[26] T. Okusaka, H. Ishii, A. Funakoshi et al., "Phase II study of single-agent gemcitabine in patients with advanced biliary tract cancer," Cancer Chemotherapy and Pharmacology, vol. 57, no. 5, pp. 647-653, 2006. 
[27] B. Gruenberger, J. Schueller, U. Heubrandtner et al., "Cetuximab, gemcitabine, and oxaliplatin in patients with unresectable advanced or metastatic biliary tract cancer: a phase 2 study," The Lancet Oncology, vol. 11, no. 12, pp. 1142-1148, 2010.

[28] H. Safran, T. Miner, M. Resnick et al., "Lapatinib/gemcitabine and lapatinib/gemcitabine/oxaliplatin: a phase I study for advanced pancreaticobiliary cancer," The American Journal of Clinical Oncology, vol. 31, no. 2, pp. 140-144, 2008.

[29] A. Morgan, "Recently approved antineoplastic agents," Oncology Practice Highlights, vol. 14, pp. 74-79, 1996. 


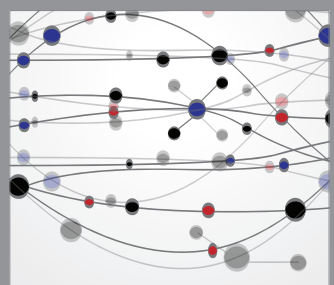

The Scientific World Journal
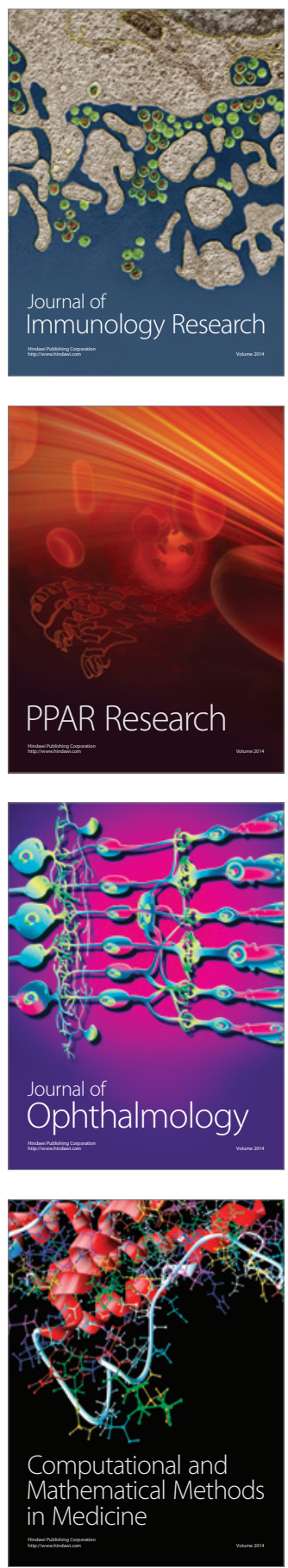

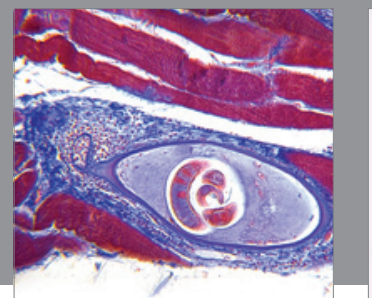

Gastroenterology

Research and Practice
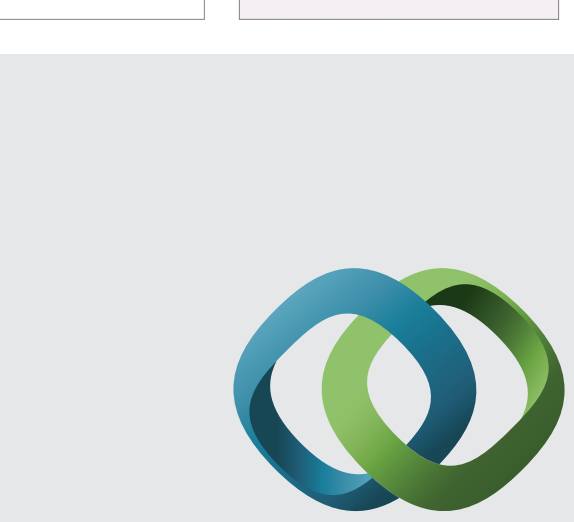

\section{Hindawi}

Submit your manuscripts at

http://www.hindawi.com
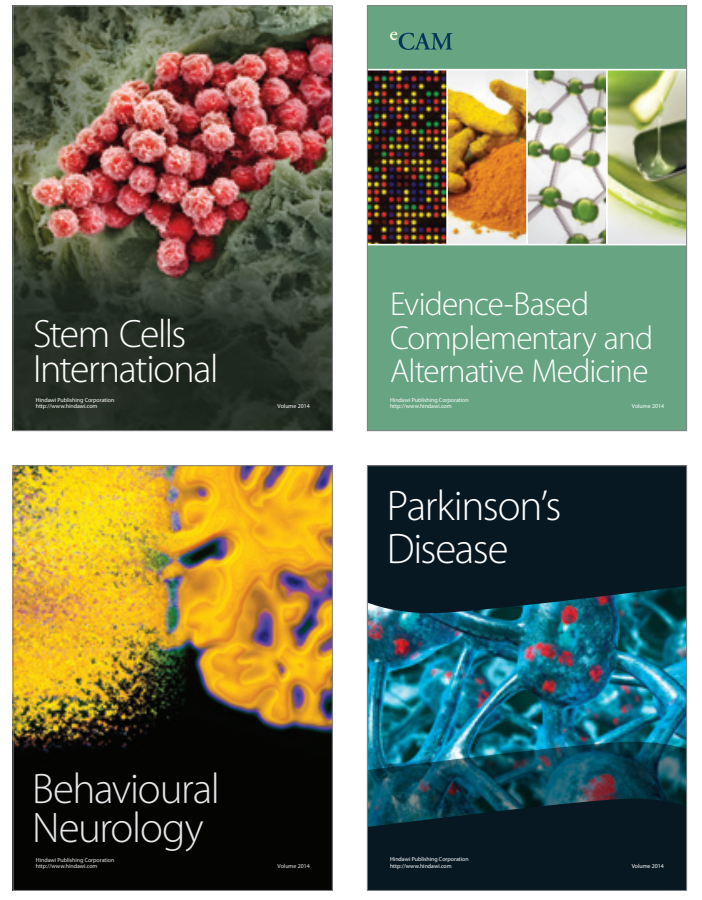
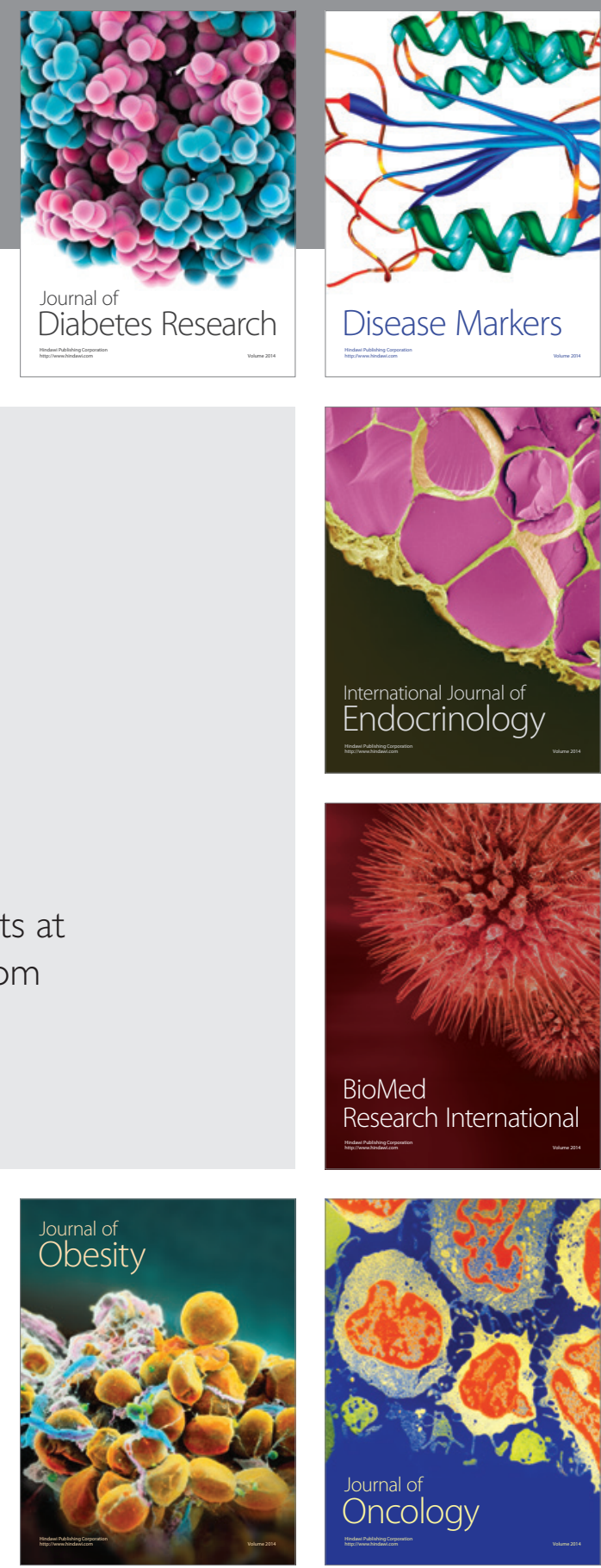

Disease Markers
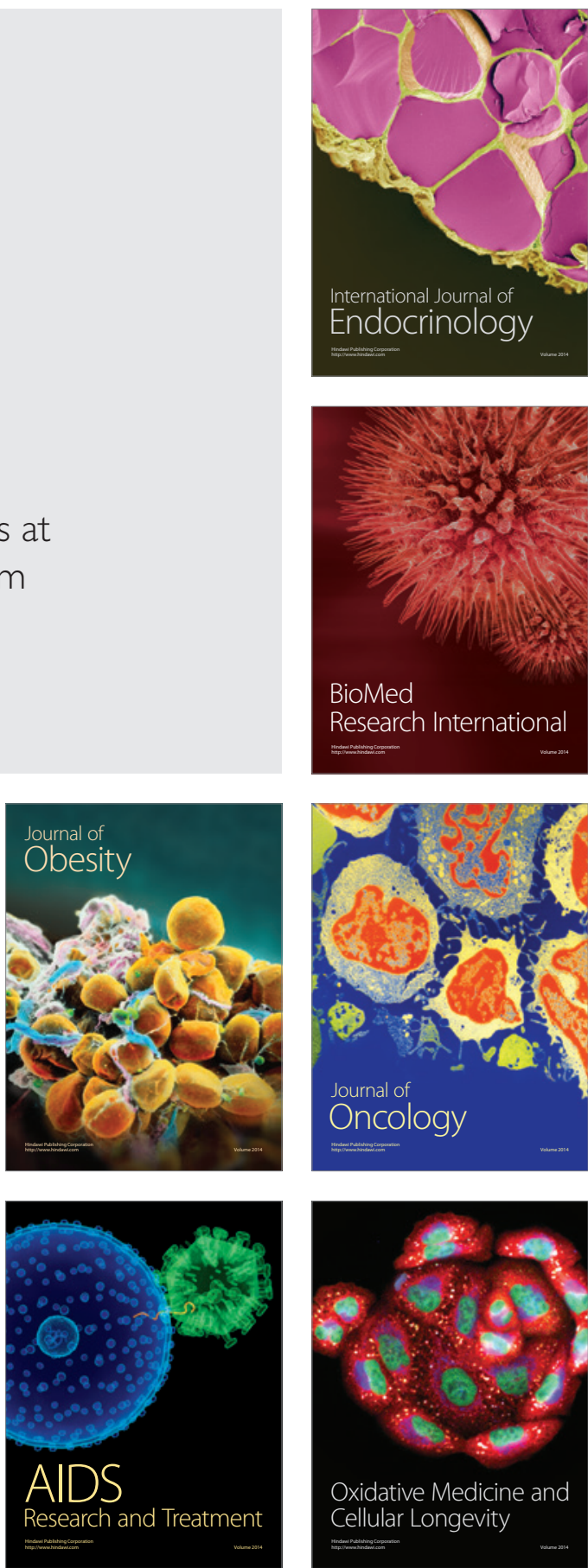